\title{
The ischemia modified albumin and mean platelet volume levels in patients with Behçet's disease
}

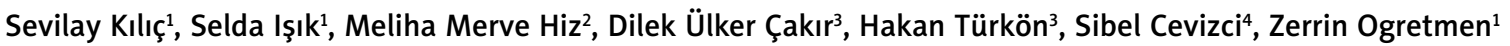 \\ ${ }^{1}$ Department of Dermatology, School of Medicine, Canakkale Onsekiz Mart University, Canakkale, Turkey \\ ${ }^{2}$ Department of Biology, Faculty of Arts and Sciences, Canakkale Onsekiz Mart University, Canakkale, Turkey \\ ${ }^{3}$ Department of Biochemistry, School of Medicine, Canakkale Onsekiz Mart University, Canakkale, Turkey \\ ${ }^{4}$ Department of Public Health, School of Medicine, Canakkale Onsekiz Mart University, Canakkale, Turkey
}

\begin{abstract}
Introduction: Behçet's disease (BD) is a chronic inflammatory disorder with endothelial dysfunction. Ischemiamodified albumin (IMA) is a marker used in the detection of diseases associated with oxidative stress, vascular endothelial cell dysfunction and ischemia. Mean platelet volume (MPV) signifies the platelet function and activity. Aim: To show whether MPV and IMA are useful in revealing the oxidative stress and the risk of thrombosis in patients with BD.

Material and methods: Twenty-six patients with BD and 28 healthy volunteers as a control group over 18 years of age were included in the study. Serum IMA and MPV levels were analyzed in both groups.

Results: The mean MPV values were identified as $0.86 \pm 0.15$ and $0.82 \pm 0.08$ (in the BD and control groups, respectively; $p=0.188$ ) and the mean IMA values were $9.39 \pm 0.73$ and $9.17 \pm 1.09$ (in the BD and control groups, respectively; $p=0.275$ ). There were no statistically significant differences between the groups. The IMA values of BD patients who were in the active phase were significant as compared to inactive BD patients and control groups ( $p=0.041)$. The IMA and MPV values of the thrombotic patients, non-thrombotic patients and control groups were not significant.

Conclusions: Ischemia-modified albumin may be a helpful marker of possible complications during an active period of BD.
\end{abstract}

Key words: Behçet's disease, ischemia-modified albumin, mean platelet volume.

\section{Introduction}

Behçet's disease (BD) is a chronic multisystemic inflammatory disorder. In 1937, Hulusi Behçet, a Turkish dermatologist, described the disease as a triad of oral aphthae, genital ulcer and uveitis. The disease is generally characterized by skin and mucous membrane lesions, central nervous system and other internal organ symptoms with visual system abnormalities [1, 2]. Since 1990, the disease's definition has been based on the International Study Group criteria as a recurrent oral aphthosis with two of the following criteria: skin lesions (erythema nodosum, papulopustular lesions), eye lesions (anterior uveitis, posterior uveitis, retinal vasculitis), genital ulcers and positive pathergy test [3]. It is well known that there is inflammation-induced thrombosis and endothelial dysfunction associated with BD [4-6].

Platelet function is a main factor in homeostasis and thrombosis. Mean platelet volume (MPV) signifies the platelet function and activity. The MPV can be associated with thrombosis in BD patients [7].

Ischemia-modified albumin (IMA) is a marker used in the detection of the myocardial ischemia. During ischemia, the metal binding capacity of the albumin decreases due to an alteration of the amino terminal end (N-terminus); metal binding site of albumin [8]. Ischemia-modified albumin levels are also reported to be increased in diseases associated with oxidative stress and vascular endothelial cell dysfunction [9].

Address for correspondence: Selda Işık, Department of Dermatology, School of Medicine, Canakkale Onsekiz Mart University, Canakkale, Turkey, phone: 054457707 50, fax: +90 286263 59 57, e-mail: seldaisik@yahoo.com.tr Received: 25.06.2015, accepted: 27.07.2015. 


\section{Aim}

The aim of this study was to see whether MPV and IMA levels are useful in revealing oxidative stress and vascular dysfunction in patients with $\mathrm{BD}$.

\section{Material and methods}

The study was carried out at the Canakkale Onsekiz Mart University, Faculty of Medicine, Department of Dermatology, Turkey. A total of 26 patients with BD and 28 controls were included in the study. Patients having any systemic disease were excluded from the study. Informed consent was obtained from all of the participants. BD diagnosis was made based on the International Study Group criteria.

All blood samples from the volunteers were collected in EDTA-containing tubes to prevent coagulation. A $500 \mathrm{ml}$ fresh blood sample was separated using other EDTA-containing tubes for MPV analyses. The remaining blood samples were centrifuged at 3,000 rpm for $10 \mathrm{~min}$ to obtain serum, and then stored at $-80^{\circ} \mathrm{C}$ until the IMA analysis. Ischemia-modified albumin levels were detected by measuring the albumin bound cobalt level in serum samples of the study participants. Therefore, a $200 \mu \mathrm{l} \mathrm{se-}$ rum sample was directly added into $50 \mu$ l of $0.1 \%$ cobalt chloride solution, and then gently mixed. After that, the sample was incubated for $10 \mathrm{~min}$ at room temperature for cobalt albumin binding. Dithiothreitol $(50 \mu \mathrm{l}$ of a $1.5 \mathrm{~g} / \mathrm{l}$ solution) was added as a colorizing agent, and then the reaction was stopped by adding $1.0 \mathrm{ml}$ of $0.9 \% \mathrm{NaCl}$ after $2 \mathrm{~min}$. The absorbance of the mixture was examined against a blind sample (a serum cobalt blank exclusion DTT) at 470 nm (Hitachi U-2900 Spectrophotometer). Beckman Coulter LH 780 analyzer (Beckman Coulter, Inc., CA, USA) was used to evaluate the MPV.

\section{Statistical analysis}

Statistical analysis was done using the Statistical Package for Social Sciences (SPSS Inc., Chicago, IL, USA), version 19.0. Compliance with the normal distribution of the variables was analyzed using the KolmogorovSmirnov test. The data mean, standard deviation, frequency, and percentage values were used in the presented descriptive data. For the comparison of the IMA and MPV values of both groups, Mann Whitney $U$ and
Kruskal-Wallis tests were used. To be considered statistically significant, $95 \%$ confidence interval and $p$-values under 0.05 were considered statistically significant.

\section{Results}

A total of 26 patients with $\mathrm{BD}$ and 28 controls were included in this study. Twenty-two (84.6\%) of the $26 \mathrm{pa}$ tients with BD were female, and $4(15.4 \%)$ were male. The mean age of the patients with $B D$ was $40.3 \pm 12.1$. The demographic characteristics of the control groups were correlated to the BD group. The mean duration of BD was $6.67 \pm 8.78$ years. Four patients with BD were smoking cigarettes and three were consuming alcohol. All of the patients had recurrent oral aphthosis and genital ulcers. Four patients had ocular association (14.8\%), 26 patients had skin lesions (erythema nodosum, papulopustular lesions) and two had a positive pathergy test. In addition, 5 patients had superficial venous thrombophlebitis. Eight patients with $B D$ were in an active phase of the disease during the study period.

At the end of the study, the mean MPV values were identified as $0.86 \pm 0.15$ and $0.82 \pm 0.08$ (in the $B D$ and control groups, respectively; $p=0.188$ ) and the mean IMA values were $9.39 \pm 0.73$ and $9.17 \pm 1.09$ (in the $B D$ and control groups, respectively; $p=0.275$ ). There were no statistically significant differences between the groups (Table 1).

When we compared BD patients in the active phase with those in an inactive phase or control groups, a significant difference was found in the IMA values ( $p=$ 0.041 ). However, we could not find the same correlation for MPV values among the groups (Table 2).

The IMA and MPV values of the thrombotic patients, non-thrombotic patients and control groups were not significant (Table 2).

\section{Discussion}

In recent years, the IMA and MPV levels have been studied in diseases related to endothelial dysfunction and oxidative stress [9-12]. The MPV, a determinant of platelet function, is considered to be an indicator of thrombosis [7]. The IMA is presented as a marker of ischemia, oxidative stress and endothelial dysfunction [8,9]. The pathogenesis of BD is not exactly known but accepted to be a mul-

Table 1. Comparison of the IMA and MPV values between the BD and control groups

\begin{tabular}{|c|c|c|c|c|c|}
\hline \multirow[t]{2}{*}{ Variables } & \multicolumn{2}{|c|}{$\mathrm{BD}(N=26)$} & \multicolumn{2}{|c|}{ Control $(N=28)$} & \multirow[t]{2}{*}{$P$-value ${ }^{\star}$} \\
\hline & Mean \pm SD & Median (min.-max.) & Mean \pm SD & Median (min.-max.) & \\
\hline IMA & $0.86 \pm 0.15$ & $0.87(0.50-1.10)$ & $0.82 \pm 0.08$ & $0.82(0.64-0.93)$ & 0.188 \\
\hline MPV & $9.39 \pm 0.73$ & $9.40(8.40-11.20)$ & $9.17 \pm 1.09$ & 9.05 (7.20-12.10) & 0.275 \\
\hline
\end{tabular}

*Mann Whitney U test; SD - Standard deviation, min. - minimum, max. - maximum. 
Table 2. The IMA and MPV values of active/inactive BD patients with/without thrombosis and the control group

\begin{tabular}{|c|c|c|c|c|}
\hline Variables & $\begin{array}{l}\text { Patients in the active state } \\
\qquad(N=8) \\
\text { Mean } \pm \text { SD }\end{array}$ & $\begin{array}{l}\text { Patients in the inactive state } \\
(N=18) \\
\text { Mean } \pm \text { SD }\end{array}$ & $\begin{array}{l}\text { Control group } \\
(N=28) \\
\text { Mean } \pm \text { SD }\end{array}$ & $P$-value* \\
\hline MPV & $9.24 \pm 0.66$ & $9.51 \pm 0.76$ & $9.24 \pm 1.25$ & 0.502 \\
\hline \multirow[t]{2}{*}{ IMA } & $0.93 \pm 0.13$ & $0.82 \pm 0.14$ & $0.83 \pm 0.07$ & 0.041 \\
\hline & $\begin{array}{l}\text { Patients with thrombosis } \\
\qquad(N=5) \\
\text { Mean } \pm \text { SD }\end{array}$ & $\begin{array}{l}\text { Patients without thrombosis } \\
\qquad(N=21) \\
\text { Mean } \pm \text { SD }\end{array}$ & $\begin{array}{l}\text { Control group } \\
(N=28) \\
\text { Mean } \pm \text { SD }\end{array}$ & \\
\hline MPV & $9.62 \pm 1.01$ & $9.38 \pm 0.66$ & $9.24 \pm 1.25$ & 0.510 \\
\hline IMA & $0.88 \pm 0.14$ & $0.85 \pm 0.15$ & $0.83 \pm 0.07$ & 0.420 \\
\hline
\end{tabular}

${ }^{*}$ Kruskal-Wallis variance analysis.

tisystemic inflammatory disease prone to thrombosis [5]. Therefore, we hypothesized that there might be a connection of the pathogenesis of BD to the IMA and MPV values. Based on our results, we found that the IMA value was remarkable during the active state of $\mathrm{BD}$.

In examining the literature, we saw different conclusions on the IMA and MPV levels in BD and other systemic diseases related to oxidative stress. As we know, there are few studies on these combinations of parameters in $\mathrm{BD}[7,11]$. Ozdemir et al. reported increased IMA levels in patients with psoriasis due to an adaptive response to oxidative stress and systemic inflammation [9]. Capkın et al. presented IMA as a marker for BD patients with vascular involvement [11]. However, Erem et al. found the IMA irrelevant to oxidative stress [13]. Similar to our study, Ozyazgan et al. revealed IMA values to be higher during the active state of BD patients [14].

Ricart et al. claimed no correlation between the MPV values and thrombosis in BD patients [15]. Conversely, Acikgoz et al. showed the MPV levels to be higher in BD patients with thrombosis [7]. Subsequently, they suggested antiplatelet therapy when accepting the MPV as a predictor of tendency to thrombosis. In our study, we did not find any significant difference regarding the MPV values in either active or inactive states of BD and in patients with or without thrombosis. So we believe that the MPV cannot be an explicit marker for determining thrombotic complications in BD.

We think that such different results indicate that the pathogenesis of oxidative stress-related diseases and pro-thrombotic diseases like BD are multi-factorial. Therefore, markers like the IMA and MPV cannot be the primary markers but may guide clinicians on the progress of the disease.

\section{Conclusions}

Based on our results, the IMA may be a helpful marker of possible complications during an active period of $\mathrm{BD}$. However, further research on this topic is needed.

\section{Acknowledgments}

This study was conducted in the Dermatology Department of the Training and Research Hospital of Canakkale Onsekiz Mart University.

\section{Conflict of interest}

The authors declare no conflict of interest.

\section{References}

1. Dąbrowska-Zimoń A, Bobrowska-Snarska D, Wódecki M, et al. Behçet's disease three successive cases in Poland. Reumatologia 2007; 45: 431-5.

2. Romańska-Gocka K, Gocki J, Placek W, et al. Behçet disease - case report and review. Post Dermatol Alergol 2009; 26: 224-8.

3. Cox NH, Jorizzo JL, Bourke JF, Savage COS. Vasculitis, neutrophilic dermatoses and related disorders. In: Rook's Textbook of Dermatology. Breathnach S, Cox N, Griffiths C, Burns T (eds.). Wiley-Blackwell, Oxford, UK 2010; 56-61.

4. Ozdemir R, Barutcu I, Sezgin AT, et al. Vascular endothelial function and plasma homocysteine levels in Behcet's disease. Am J Cardiol 2004; 94: 522-5.

5. Emmi G, Silvestri E, Squatrito D, et al. Thrombosis in vasculitis: from pathogenesis to treatment. Thromb J 2015; $13: 15$.

6. Tursen B, Alp R, Tursen $U$, et al. Activation parameters in Behçet's disease. Hong Kong J Dermatol Venereol 2014; 22: 5-11.

7. Acikgoz N, Karıncaoglu Y, Ermis N, et al. Increased mean platelet volume in Behçet's disease with thrombotic tendency. Tohoku J Exp Med 2010; 221: 119-23.

8. Lippi G, Montagnana M, Salvagno GL, et al. Potential value for new diagnostic markers in the early recognition of acute coronary syndromes. CJEM 2006; 8: 27-31.

9. Ozdemir M, Kivici A, Balevi A, et al. Assessment of ischaemia-modified albumin level in patients with psoriasis. Clin Exp Dermatol 2012; 37: 610-4.

10. Aydin O, Ellidag HY, Eren E, et al. Ischemia modified albumin is an indicator of oxidative stress in multiple sclerosis. Biochem Med 2014; 24: 383-9.

11. Capkin E, Karkucak M, Kola M, et al. Ischemia-modified albumin (IMA): a novel marker of vascular involvement in Behçet's disease? Joint Bone Spine 2015; 82: 68-9. 
12. Topaloğlu N, Yıldırım Ş, Tekin M, et al. Mean platelet volume and ischemia modified albumin levels in cord blood of infants of diabetic mothers. Pediatr Neonatol 2014; 55: 455-8.

13. Erem C, Suleyman AK, Civan N, et al. Ischemia-modified albümin and malondialdehyde levels in patients with overt and subclinical hyperthyroidism: effects of treatment on oxidative stress. Endocr J 2015; 62: 493-501.

14. Ozyazgan S, Andican G, Erman H, et al. Relation of protein oxidation parameters and disease activity in patients with Behçet's disease. Clin Lab 2013; 59: 819-25.

15. Ricart JM, Espańa F, Navarro S, et al. Mean platelet volume does not seem to relate to thrombosis or posterior uveitis in Behçet's disease. Clin Hemorheol Microcirc 2013; 54: 51-7. 